\title{
Efeito da Lei 11.638/07 sobre o conservadorismo condicional das empresas listadas BM\&FBOVESPA*
}

\section{Efect of Law 11.638/07 on conditional conservatismo companies listed on BM\&FBOVESPA}

Luis Paulo Guimarães dos Santos

Professor Assistente da Faculdade de Ciências Contábeis da Universidade Federal da Bahia.

E-mail: lupa@ufba.br

Gerlando Augusto Sampaio Franco de Lima

Professor Doutor do Departamento de Contabilidade e Atuária da Faculdade de Economia, Administração e Contabilidade da Universidade de São Paulo.

E-mail: gerlando@usp.br

Sheizi Calheira de Freitas

Professora Assistente da Faculdade de Ciências Contábeis da Universidade Federal da Bahia.

E-mail: shecal@ufba.br

Iran Siqueira Lima

Professor Doutor do Departamento de Contabilidade e Atuária da Faculdade de Economia, Administração e Contabilidade da Universidade de São Paulo.

E-mail: iranlima@uol.com.br

Recebido em 13.10.2010 - Aceito em 21.12.2010 - $2^{a}$. versão aceita em 04.03.2011

\section{RESUMO}

A Lei $n^{\circ} 11.638 / 07$ alterou, substancialmente, as normas e práticas brasileiras de contabilidade e tais mudanças poderão ter impactos significativos no conservadorismo dos resultados contábeis divulgados. Conhecer o papel do conservadorismo e seus determinantes é importante para compreender a natureza, finalidade e implicações das estimativas contábeis. Este estudo teve como objetivo investigar se a promulgação da Lei n ${ }^{\circ}$ 11.638/07 alterou o grau de conservadorismo contábil condicional de empresas brasileiras listadas na Bovespa e BMF BOVESPA. Para tanto, procedeu-se a uma pesquisa empírico-analítica por meio de coleta de informações relativas às companhias não financeiras de capital aberto que estavam listadas na Bolsa durante o período que compreendeu o primeiro trimestre de 2005 até o terceiro trimestre de 2009, no banco de dados Economática ${ }^{\circ}$ O modelo de Basu foi ajustado para medir o efeito da Lei ${ }^{\circ}$ 11.638/07 no conservadorismo condicional. Na hipótese de conservadorismo, os ganhos refletem más notícias (retornos negativos) mais rapidamente do que boas notícias (retornos positivos). Nesse modelo, a medida do conservadorismo (tratamento assimétrico dos ganhos e perdas) baseia-se na extensão em que a associação lucro-retorno é mais forte durante os períodos de más notícias, em comparação com os períodos de boas notícias. Para a amostra analisada, não é possível inferir se as novas regras tiveram algum efeito sobre o grau de reconhecimento assimétrico de perdas e ganhos. Todavia, importa observar que, em função do período de tempo abrangido, os resultados apresentados são preliminares e estão limitados pelo modelo de análise de dados adotado e pelas características da amostra utilizada no estudo, não levando em consideração outros importantes aspectos relacionados ao processo de adoção das normas internacionais de contabilidade.

*Artigo apresentado no $10^{\circ}$. Congresso USP de Controladoria e Contabilidade, São Paulo, SP, 2010. 
Palavras-chave: Lei no 11.638/07. Conservadorismo. Normas Internacionais de Contabilidade. IFRS.

\section{ABSTRACT}

Law $n^{\circ} 11.638 / 07$ has substantially changed Brazilian accounting practices and standards, and such changes can exert significant impacts on earnings conservatism. Understanding the role of conservatism and its determinants is important to interpret the nature, purpose and implications of accounting estimates. This study aimed to investigate whether the promulgation of Brazilian Law $n^{\circ} 11.638 / 07$ changed the degree of conditional accounting conservatism of Brazilian companies listed on Bovespa \& BMF BOVESPA. An empirical analytical research was carried out collecting information about non-financial companies listed on the Brazilian Stock Exchange from the first quarter of 2005 to the third quarter of 2009 in the Economatica ${ }^{\circledR}$ system. Basu's model was adjusted to measure the effect of Law $n^{\circ} 11.638 / 07$ on conditional conservatism. In conservativeness hypotheses, earnings reflect bad news (negative stock returns) more quickly than good news (positive stock returns). In this model, the measure of conservatism (asymmetrical treatment of gains and losses) is based on the extent to which the earnings-return association is stronger during periods of bad news as compared with periods of good news. For the sample analyzed, results suggest that it cannot be inferred whether the new rules had some effect on the degree of asymmetric recognition of gains and losses.

Keywords: Law $n^{\circ}$ 11.638/07. Conservatism. International Accounting Standards. IFRS.

\section{INTRODUÇÃO}

Há muito se discute a relevância da contabilidade para o desenvolvimento dos mercados financeiros, em litígios e monitoramento de contratos entre os agentes econômicos, bem como o papel que os padrões contábeis desempenham na qualidade da informação divulgada e seu evidente impacto na redução da assimetria de informação, na eficiência das decisões de alocação de recursos, na redução de conflito de agentes e redução de custos de transação. A literatura contábil internacional tem fornecido várias evidências da relevância e das consequências econômicas da informação contábil.

A existência de padrões contábeis distintos afeta a qualidade da informação contábil para fins de divulgação, dificulta a avaliação e comparação do desempenho e da eficiência econômica de companhias que atuam em vários países, em função de estarem sujeitas a uma grande variedade de normas contábeis. Todavia, os padrões internacionais de contabilidade fornecem uma maneira interessante de analisar as consequências econômicas da informação financeira (SODERSTROM, 2007), pois permitem que os agentes econômicos possam cotejar os resultados das empresas por meio de um conjunto unificado de conceitos e critérios de mensuração e tomar suas decisões a partir do julgamento que fizerem sobre elas.

Desde 2005, as Normas Internacionais de Contabilidade (International Financial Reporting Standars - IFRS) emitidas pelo Comitê Internacional de Padrões Contábeis (International Accounting Standards Board IASB) vêm sendo adotadas por vários países da Europa (por exemplo, todas as companhias listadas em Bolsas de Valores dos vinte e cinco países-membro da União Europeia são obrigadas a elaborar suas demonstrações contábeis segundo as normas internacionais) com previsão de acolhimento, nos próximos anos, por parte de outras importantes nações (por exemplo, o Canadá em 2011 e os EUA em 2014).

De acordo com Soderstrom (2007), o aprimoramento do ambiente de informação, 
em decorrência da adoção das IFRS, está associado a pelo menos dois fatores:

i) A melhoria baseia-se na premissa de que a mudança para as IFRS constitui uma alteração de princípios contábeis que induz à maior qualidade de relatórios financeiros. Evidências sugerem que empresas que adotam as IFRS têm menos earnings management, mais reconhecimento oportuno de perdas e mais value relevance do lucro contábil (BARTH, LANDSMAN e LANG , 2006);

ii) $\mathrm{O}$ arcabouço legal influencia o sistema financeiro dos países. O sistema de contabilidade é um componente complementar do sistema institucional global do país e é determinado por meio dos incentivos que as empresas recebem para a divulgação de informações financeiras. Países com tradição common law têm melhor sistema de proteção para os investidores e o lucro contábil é significativamente mais oportuno que aqueles com tradição civil law (BALL, KOTHARI e ROBIN, 2000; LA PORTA, LOPEZ-DE-SILANES e SHLEIFER, 1998).

Outros fatores, tais como: sistema tributário, estrutura de propriedade, sistema político, estrutura de capital e desenvolvimento do mercado de capitais, estão relacionados à qualidade da divulgação financeira. Por isso, as consequências econômicas da mudança do sistema contábil podem variar entre os países (SODERSTROM, 2007).

O IASB, em seu Framework for the Preparation and Presentation of Financial Statements, considera que as demonstrações contábeis têm como objetivo precípuo fornecer informações úteis para a avaliação e tomada de decisão econômica dos diversos usuários da informação contábil sem ter o propósito de atender necessidades distintas de determinados grupos de usuários. Desse modo, o que denota a utilidade das demonstrações contábeis são suas características qualitativas, dentre as quais se destacam: a compreensibilidade, a relevância, a confiabilidade e a comparabilidade. Tais característi- cas descrevem, na verdade, atributos desejáveis e esperados dos relatórios de divulgação financeira delineados em concordância com o padrão contábil contido nas IFRS.

Entre as características que imputam utilidade à informação contábil divulgada, a confiabilidade é uma das que mais se destaca. É a partir desse atributo que os agentes econômicos avaliam e formam sua própria opinião sobre se o que está contido nas demonstrações, de fato, representa a realidade econômica, financeira e patrimonial da entidade que está sendo reportada. Para o IASB, informação contábil confiável é aquela com ausência de vieses relevantes. Nesse contexto, o conservadorismo representa um mecanismo fundamental da estrutura conceitual básica da contabilidade que favorece a divulgação de informações enviesadas.

O princípio do conservadorismo, que se sustenta na ideia de se reconhecer de forma mais oportuna as perdas não realizadas em relação aos ganhos não realizados, tem caracterizado, durante séculos, a prática contábil. Apesar de seu uso generalizado por vários países ao longo do tempo, seu conceito é um pouco contra-intuitivo e várias questões relacionadas às implicações de seu uso na preparação de relatórios contábeis para fins de divulgação financeira têm sido a base para diversas pesquisas acadêmicas recentes (GOTTI, 2007).

A necessidade de conservadorismo é, frequentemente, associada à divulgação confiável de eventos passados. Entretanto, o objetivo das atuais normas internacionais de contabilidade é, essencialmente, orientado para o futuro, com o fim de auxiliar os investidores e outras partes interessadas em suas decisões. Assim, o conservadorismo não é um princípio contábil que rege as IFRS. O que se espera das demonstrações financeiras, à luz das IFRS, é que sejam compreensíveis, relevantes, confiáveis e comparáveis, mas sem um viés conservador (HELLMAN, 2008).

Uma das razões para a adoção dos padrões internacionais de contabilidade parece ser evi- 
tar a aplicação inconsistente e exagerada do princípio contábil do conservadorismo e suas implicações mais comuns: surgimento de reservas ocultas e excessiva criação de provisões na contabilidade (HELLMAN, 2008). Todavia, conforme aponta Watts (2003), a regulação da contabilidade fornece incentivos para as empresas apresentarem demonstrações contábeis mais conservadoras. $\mathrm{O}$ entendimento das motivações e determinantes do conservadorismo é importante para se obterem insights sobre o papel da informação contábil na intermediação de contratos entre agentes, incentivos gerenciais, redução de assimetria informacional e contextos institucionais (GOTTI, 2007).

No Brasil, a promulgação da Lei no ${ }^{\circ} 11.638 / 07$ tem ocasionado modificações substanciais nas práticas e nos padrões contábeis em uso no país, especialmente no que se refere à avaliação de itens patrimoniais e reestruturação do grupo patrimônio líquido, dando ênfase à essência sobre a forma e ao o conceito de valor justo, visando espelhar a realidade econômica das entidades e do seu patrimônio, demonstrando-o a valor mais próximo ao de mercado. As mudanças promovidas estão permitindo o alinhamento das normas e práticas contábeis adotadas nacionalmente às normas internacionais. Tais mudanças podem ter impactos significativos em dois aspectos diretamente relacionados à qualidade da informação contábil divulgada: a oportunidade e o conservadorismo.

Com o advento da Lei $\mathrm{n}^{\circ} 11.638 / 07$, o processo brasileiro de convergência às normas internacionais passou a ser um amplo e articulado esquema de regulação que envolve o Estado, por intermédio de seus órgãos reguladores de normas contábeis como, por exemplo, a Comissão de Valores Mobiliários (CVM), o Banco Central do Brasil e a Supe- rintendência de Seguros Privados (SUSEP); além de órgãos privados, tal como o Comitê de Pronunciamentos Contábeis (CPC), entidade de direito privado criado pelo Conselho Federal de Contabilidade (CFC), em 2005, que tem como objetivo realizar estudos, preparar e emitir Pronunciamentos Técnicos de contabilidade "para permitir a emissão de normas pela entidade reguladora brasileira [...] levando sempre em conta a convergência da Contabilidade Brasileira aos padrões internacionais" (Art. 30 - Resolução CFC no $1.055 / 05)$. A lei supracitada pode ser considerada como o marco regulatório que estabelece a convergência do Brasil às normas internacionais de contabilidade.

Conforme justificativas apresentadas, tem-se como objetivo principal investigar se, após a vigência da Lei no $11.638 / 07$, houve alteração no grau de conservadorismo condicional das empresas brasileiras listadas na Bolsa de Valores de São Paulo. Nesse sentido, pretende-se encontrar resposta para a seguinte questão: a vigência da Lei no ${ }^{\circ} 11.638 / 07$ afetou o grau de conservadorismo condicional dos resultados contábeis divulgados pelas companhias que negociam suas ações na BMF\& BOVESPA?

Como consequência da questão levantada, o desenvolvimento do trabalho será orientado pelas seguintes hipóteses:

$\mathrm{H}_{1}$ - $\mathrm{O}$ conservadorismo nos lucros divulgados pelas companhias que negociam suas ações na BMF\&BOVESPA aumentou depois da Lei n. ${ }^{\circ} 11.638$.

$\mathrm{H}_{2}$ - A vigência Lei $n^{\circ} 11.638$ não teve influência significativa no nível de conservadorismo nos lucros divulgados pelas companhias que negociam suas ações na BMF\&BOVESPA.

\section{REVISÃO DA LITERATURA}

Compreender o papel do conservadorismo, seus determinantes e suas variações entre as empresas é importante para a interpreta- ção da natureza, propósitos e implicações da avaliação contábil (GOTTI, 2007). Tradicionalmente, dentro da estrutura conceitual bá- 
sica da contabilidade, esse princípio tem sido descrito como o procedimento contábil de se escolher, dentre mais de uma maneira igualmente válida e economicamente viável, o registro de eventos econômicos que demonstre o menor valor para o patrimônio líquido de uma entidade. Isso ocorre, geralmente, pela adoção de práticas contábeis que exprimam menores valores para receitas e ativos e maiores valores para despesas e passivos. O objetivo central do conservadorismo é antecipar o reconhecimento de perdas e nunca o de ganhos.

Belkaoui (2004) aponta que o conservadorismo exige uma atitude pessimista do contador quando da escolha de procedimentos contábeis para a elaboração de demonstrações financeiras, pois esse princípio determina que, ao escolher entre dois ou mais procedimentos contábeis geralmente aceitos, deve ser demonstrada preferência para a opção que tenha o menor impacto favorável ao patrimônio líquido. Em outras palavras, deve ser dada preferência aos procedimentos contábeis que notifiquem menor valor para ativos e receitas e maior valor para passivos e despesas.

Nessa mesma direção, Hendriksen e Breda (1991) explicam que o termo conservadorismo é, geralmente, utilizado para dizer que os contadores deveriam reportar, dentre os vários possíveis, o menor valor para ativos e receitas e maior valor para passivos e despesas. Os autores esclarecem, ainda, que, sob esse princípio, as despesas deveriam ser reconhecidas mais cedo e as receitas mais tarde. Assume-se que, para fins de divulgação financeira, a postura pessimista é preferível à otimista.

De acordo com o Financial Accounting Standards Board (FASB), em seu Concepts Statement $\mathrm{n}^{\circ} 2$, o conservadorismo é uma reação prudente para tentar garantir que a incerteza e os riscos inerentes a situações de negócios sejam devidamente considerados. Pelo que se observa, esse conceito difere da visão tradicional vista anteriormente. Todavia, Yinping (2004) acentua que a definição do FASB é ambígua, pois não especifica a natureza do que significa "reação prudente" nem explica como tal reação pode assegurar que os riscos sejam considerados de maneira adequada.

Apesar de se constituir em um dos pilares da prática contábil atual, o princípio do conservadorismo é antigo e bastante criticado por práticos e teóricos da contabilidade. De acordo com Kam (1990), tais críticas podem ser sumarizadas do seguinte modo:

- A observância do conservadorismo torna os procedimentos contábeis adotados pela firma inconsistentes na mediação do lucro, pois, quando ocorre a subavaliação de um ativo, no futuro haverá uma avaliação exagerada do lucro quando o ativo for utilizado ou vendido.

- O grau de conservadorismo nas demonstrações contábeis é uma questão de conveniência, pois decorre de política por parte da firma.

- Mesmo que se saiba que a contabilidade seja conservadora, é difícil para o investidor determinar o montante de subavaliação de um ativo. Esse fato o coloca em posição de desvantagem e confere vantagem oportunista aos insiders.

- Em muitas situações, a observância do conservadorismo contradiz a aplicação de outros princípios contábeis. Por exemplo, a regra do custo ou mercado viola o princípio do custo histórico.

- Por sua natureza, o conservadorismo provoca viés sistemático nas informações contábeis divulgadas em lugar de possibilitar uma avaliação realística da entidade que está sendo reportada.

- O conservadorismo está tão arraigado nas práticas contábeis que se tornou mais uma atitude, estado de espírito dos contadores, que uma forma conveniente de responder à incerteza.

Apesar de estar sujeito a várias críticas, o conservadorismo na contabilidade tem suas 
justificativas. Por exemplo, Hendriksen e Breda (1991) argumentam que a tendência pessimista dos contadores é necessária para compensar a tendência natural ao otimismo dos gestores e dos proprietários, tendo em vista que o exagero na mensuração do lucro e avaliações é mais prejudicial para o negócio e os proprietários que a sua suavização. Kam (1990), adicionalmente, destaca que os usuários, especialmente os credores, necessitam conhecer, com certa margem de segurança, a posição financeira da entidade para poderem se proteger de consequências adversas. Os defensores do conservadorismo afirmam que essa prática contábil subsiste e continua a ser seguida porque os anos de experiência têm demonstrado ser uma convenção útil e prudente em um ambiente cheio de incerteza.

Gotti (2007) pontua que, mais recentemente, a literatura empírica introduziu uma distinção entre dois tipos diferentes de conservadorismo. O primeiro é o conservadorismo incondicional que ocorre com a contabilização dos custos da maioria dos bens intangíveis e se reflete na subavaliação da razão book-to-market. Essa forma, também, é conhecida como conservadorismo do balanço. O segundo é o conservadorismo condicional, definido como a oportunidade assimétrica de reconhecimento de ganhos e perdas no lucro contábil. Essa forma é, igualmente, chamada de conservadorismo do lucro.

$\mathrm{Na}$ literatura empírica, a forma mais comum de estudo do conservadorismo é como o reconhecimento assimétrico, pelo lucro contábil, das más notícias em relação às boas (BASU, 1997). Nessa perspectiva, esse princípio contábil é visto como a exigência de um alto padrão de verificação para reconhecer informações favoráveis (boas notícias) como ganhos, o que não ocorre com as más notícias como perdas. Como consequência, o lucro contábil reflete as más notícias em uma base mais oportuna que as boas notícias, estabelecendo um padrão de reconhecimento assimétrico entre perdas e ganhos na con- tabilidade. Essa prática é consistente com a alta qualidade do lucro contábil (WATTS e ZIMMERMAN, 1986; BASU, 1997; BALL, KOTHARI e ROBIN, 2000; WATTS 2003a e 2003b; FRANCIS et al., 2005; BALL e SHIVAKUMAR, 2005 e 2006).

Uma consequência importante do tratamento assimétrico dos ganhos e perdas é a subavaliação do patrimônio líquido. Reguladores do mercado, organismos de normalização e acadêmicos têm criticado o conservadorismo argumentando que subavaliação em períodos atuais pode conduzir a uma sobrevalorização dos lucros futuros, causando uma subavaliação das despesas que estão por vir (WATTS, 2003a).

Outro aspecto importante que tem sido documentado por algumas pesquisas internacionais é o fato de que características institucionais e legais estão fortemente associadas à demanda pelo lucro contábil e à forma como ele incorpora o lucro econômico. O lucro contábil em países com tradição civil law é menos oportuno, particularmente na incorporação de perda econômica. Fatores como regulação, tributação e litígio são importantes determinantes da demanda pelo lucro contábil nesses países (BALL, KOTHARI e ROBIN, 2000; BUSHMAN e PIOTROSKI, 2005; BARTH, LANDSMAN e LANG, 2006).

O lucro contábil em países common law é, significativamente, mais oportuno que em países civil law. Isso ocorre devido ao fato de haver a rápida incorporação da perda econômica pelo lucro contábil num ambiente de conservadorismo. Além disso, naqueles países é mais provável resolver problemas de assimetria de informação em função de outras características institucionais que não as demonstrações contábeis públicas oportunas e conservadoras. A oportunidade e o conservadorismo juntos capturam mais o conceito de transparência das demonstrações contábeis (BALL, KOTHARI e ROBIN, 2000).

No cenário nacional, antes da convergência para as IFRS, os princípios de contabili- 
dade geralmente aceitos no Brasil estavam definidos na Resolução CFC No 750/93. Nos termos dela; o conservadorismo recebia o nome de Princípio da Prudência, sendo descrito da seguinte maneira:

O Princípio da PRUDÊNCIA determina a adoção do menor valor para os componentes do ATIVO e do maior para os do PASSIVO, sempre que se apresentem alternativas igualmente válidas para a quantificação das mutações patrimoniais que alterem o patrimônio líquido.

Como consequência, tal princípio impõe a escolha da hipótese de que resulte menor patrimônio líquido, quando se apresentarem opções igualmente aceitáveis diante dos demais Princípios Fundamentais de Contabilidade.

O CPC aprovou o Pronunciamento Conceitual Básico - Estrutura Conceitual para a Elaboração e Apresentação das Demonstrações Contábeis, que, posteriormente, foi referendado pela CVM (Deliberação CVM no 539/08), pelo CFC (NBC T 1 - Resolução no 1.121/08), além de outras agências reguladoras. Desse modo, o padrão contábil nacional básico está definido nesse instrumento que prevê a existência da Prudência como um dos componentes da Confiabilidade, sendo essa uma das características qualitativas da informação contábil.

De acordo com o CFC, em sua NBC T1, Prudência consiste no emprego de certo grau de precaução no exercício dos julgamentos necessários às estimativas em certas condições de incerteza, no sentido de que ativos ou receitas não sejam superestimados e que passivos ou despesas não sejam subestimados. Entretanto, o exercício da prudência não permite, por exemplo, a criação de reservas ocultas ou provisões excessivas, a subavaliação deliberada de ativos ou receitas, a superavaliação deliberada de passivos ou despesas, pois as demonstrações contábeis deixariam de ser neutras e, portanto, não seriam confiáveis.

Além da ampla discussão normativa sobre o conservadorismo, no Brasil tem-se verificado muitos trabalhos empíricos sobre esse tema. Alguns exemplos estão elencados no Quadro 1.

Quadro 1 Pesquisas Empíricas Brasileiras sobre Conservadorismo

\begin{tabular}{|l|l|}
\hline AUTOR: & INVESTIGOU: \\
\hline Gonzaga e Costa (2009) & $\begin{array}{l}\text { relação do conservadorismo contábil com os conflitos sobre as políticas de di- } \\
\text { videndos entre acionistas minoritários e controladores nas companhias abertas } \\
\text { listadas na Bovespa no período de } 1995 \text { a } 2006 .\end{array}$ \\
\hline Coelho, Cia e Lima (2008) & $\begin{array}{l}\text { a diferença no conservadorismo condicional na divulgação de lucros entre } \\
\text { companhias abertas brasileiras emissoras e não emissoras de ADRs. }\end{array}$ \\
\hline Paulo, Antunes e Formigoni (2008) & o conservadorismo contábil nas companhias abertas e fechadas brasileiras. \\
\hline Moreira et al. (2009) & $\begin{array}{l}\text { o conservadorismo e a qualidade informacional dos resultados contábeis publi- } \\
\text { cados por siderúrgicas brasileiras. }\end{array}$ \\
\hline Brito, Lopes e Coelho (2008) & $\begin{array}{l}\text { o conservadorismo nos resultados contábeis de instituições financeiras estatais } \\
\text { e privadas que atuam no Brasil. }\end{array}$ \\
\hline Gonzaga (2008) & $\begin{array}{l}\text { a relação entre conservadorismo contábil e os conflitos entre acionistas sobre } \\
\text { políticas de dividendos e o custo da dívida. }\end{array}$ \\
\hline Costa (2004) & a aplicação do conservadorismo em cinco países da América do Sul. \\
\hline Antunes (2007) & $\begin{array}{l}\text { o impacto da adesão aos níveis de governança da BOVESPA na qualidade da } \\
\text { informação contábil. }\end{array}$ \\
\hline Mendonça (2008) & $\begin{array}{l}\text { o impacto da Lei Sarbanes-Oxley (Sox) no conservadorismo contábil das em- } \\
\text { presas brasileiras que emitiram ADR antes de 2002. }\end{array}$ \\
\hline
\end{tabular}


continuação

\begin{tabular}{|l|l|}
\hline AUTOR: & INVESTIGOU: \\
\hline Costa (2008) & $\begin{array}{l}\text { o impacto da regulação diferenciada no conservadorismo nas empresas brasi- } \\
\text { leiras no período de } 1996 \text { a } 2006 .\end{array}$ \\
\hline Coelho (2007) & $\begin{array}{l}\text { se os resultados contábeis, das companhias de capital aberto e fechado, pu- } \\
\text { blicados no Brasil apresentavam reconhecimento tempestivo e assimétrico de } \\
\text { perdas econômicas na ocorrência de sinais contemporâneos de mau desempe- } \\
\text { nho, entre o período de } 1995 \text { a 2004. }\end{array}$ \\
\hline Kaizer (2007) & $\begin{array}{l}\text { o impacto da regulamentação contábil no conservadorismo nas empresas do } \\
\text { setor elétrico do Brasil. }\end{array}$ \\
\hline Santos (2006) & $\begin{array}{l}\text { o conservadorismo contábil e o timeliness nas demonstrações contábeis em US } \\
\text { GAAP E BR GAAP das empresas brasileiras com ADRs. }\end{array}$ \\
\hline
\end{tabular}

\section{DESENHO DA PESQUISA E TRATAMENTO DOS DADOS}

Sob a abordagem positiva, procedeu-se a uma pesquisa empírico-analítica mediante a coleta de informações, no banco de dados Economática ${ }^{\circledast}$ relativa às companhias não financeiras de capital aberto que estavam listadas na BOVESPA, durante o período que compreendeu o primeiro trimestre de 2005 até o terceiro trimestre de 2009, e apresentaram as demonstrações contábeis trimestrais para todos os trimestres, nessa janela de tempo. Com o filtro estabelecido, foram identificadas 357 companhias ativas, sendo que apenas 100 tinham todas as informações requeridas disponíveis nos dezessete trimestres da série de tempo fixada. Optou-se por trabalhar com as demonstrações contábeis não consolidadas.

Inicialmente, os dados coletados foram tratados descritivamente, tendo sido apuradas as médias, desvio-padrão e variância das variáveis do estudo, além de elaboração de gráfico e tabelas visando à organização e sumarização dos dados obtidos a partir das demonstrações contábeis das empresas.

Para medição do conservadorismo condicional das empresas foi utilizado o modelo analítico original proposto por Basu (1995), ajustado para medir o efeito da Lei n. ${ }^{\circ} 11.638$ sobre o conservadorismo conforme descrito a seguir. Os resultados apurados foram utilizados para testar as hipóteses do trabalho. a) Equação 1 - Modelo Original

$X_{i t} / P_{i t-1}=\alpha_{0}+\alpha_{l} D R_{i t}+\beta_{0} R_{i t}+\beta_{l} R_{i t} D R_{i t}$ em que:

- $X_{i t}$ é o lucro por ação da empresa $i$ no ano $t$;

- $P_{i t-1}$ é o preço por ação no início do ano;

- $R_{i t}$ é o retorno da empresa $i$ no ano $t$, calculado da seguinte forma: $P_{i t}-P_{i t-1}$;

- $D R_{i t}$ é uma variável Dummy que assume valor 1 quando $R_{i t}<0$ e 0 em outras situações.

b) Equação 2 - Modelo modificado

$X_{i t} / P_{i t-1}=\alpha_{0}+\alpha_{1} D R_{i t}+\beta_{0} R_{i t}+\beta_{1} R_{i t} D R_{i t}$ $+\beta_{2} D T_{i t}+\beta_{3} D T_{i t} R_{i t} D R_{i t}$

em que:

- $X_{i t}$ é o lucro por ação da empresa $i$ no trimestre $t$;

- $P_{i t-1}$ é o preço por ação no início do trimestre;

- $R_{i t}$ é o retorno da empresa $i$ no ano $t$, calculado da seguinte forma: $P_{i t}-P_{i t-1}$;

- $D R_{i t}$ é uma variável Dummy que assume valor 1 quando $R_{i t}<0$ e 0 em outras situações;

- DT é uma variável Dummy de trimestre. Será 1 para os trimestres dos anos de 2008 e 2009 e 0 para os anos anteriores. 
Os ajustes ao modelo analítico original compreenderam a inclusão de uma variável dummy de trimestre para tentar capturar o feito da mudança no nível de conservadorismo das empresas a partir de 2008, além da inclusão das informações sobre lucro por ação e retorno econômico em frequência trimestral (balanços intermediários). Esse último ajuste foi necessário em função de não existir uma série histórica sobre essas informações em base anual ampla.

O reconhecimento assimétrico de perdas econômicas indica que o lucro reflete as más notícias mais rapidamente que as boas notícias. A ideia subjacente ao modelo analítico adotado é que o preço das ações é mais importante que o lucro contábil porque reflete informações recebidas de outras fontes além do lucro corrente (BEAVER, LAMBERT e MORSE, 1980; KOTHARI e SLOAN, 1992; BASU, 1997). O conservadorismo, no lucro contábil, torna-o mais oportuno e sensível às más notícias que às boas. Desse modo, em uma regressão linear, a relação lucro-retorno é prevista para ser mais forte para retornos negativos inesperados que para retornos positivos inesperados. O conservadorismo aumenta a oportunidade do lucro na divulgação de más notícias (BASU, 1997; BALL, KOTHARI e ROBIN, 2000).

Em ambas as equações (modelo original e ajustado), o coeficiente $\beta_{0}$ mede a oportunidade do lucro contábil em capturar o efeito de boas e más notícias. O reconhecimento assimétrico de perda econômica em relação aos ganhos representa o conservadorismo condicional. Esse é capturado pelos coeficientes $\beta_{1}$ e $\alpha_{1}$. Na presença de conservadorismo, espera-se que o coeficiente $\beta_{1}$ seja positivo e o $\alpha_{1}$ seja negativo, ambos estatisticamente significativos. Por seu turno, o coeficiente $\beta_{3}$ medirà a magnitude do conservadorismo incondicional sob a presença do padrão contábil estabelecido a partir da Lei no 11.638. Espera-se que seu valor, igualmente, seja positivo e estatisticamente significativo no caso de aumento do conservadorismo, após a vigência da referida lei.

Por meio da técnica de dados em painel, foram estimadas todas as regressões utilizadas pelo modelo supracitado com o emprego do software STATA/SE 9.2. O painel adotado foi equilibrado com efeito aleatório, definido mediante os testes Breusch-Pagan e Hausman, e abordagem robusta. Nesse caso, foram utilizados estimadores de Mínimos Quadrados Ordinários (OLS) consistentes com um estimador diferente da matriz de variância-covariância dos estimadores dos parâmetros (modelo vetorial de correção de erros) que leva em conta os erros não independentes e identicamente distribuídos.

Nesse ponto, cabe serem destacadas algumas limitações na metodologia adotada: i) a amostra utilizada é não probabilística. Por conseguinte, sua representatividade em relação à população alvo não poder ser considerada. Assim, os resultados encontrados não têm a faculdade de generalização para todas as empresas que atuam na BMF \& BOVESPA; ii) a pesquisa fez uso de demonstrações financeiras trimestrais. Nesse caso, impende salientar o fato de as empresas estarem desobrigadas de publicar os relatórios contábeis intermediários de 2008 observando as determinações da Lei no $11.638 / 07$ e da Medida Provisória no 449/08. Isso significa que, em termos de padrão contábil, as demonstrações intermediárias podem não capturar diferença estrutural significativa após o ano de 2007. "Pelo interesse de tempestividade e considerações de custos, bem como para evitar repetições de informações previamente divulgadas, a entidade pode ser requerida a divulgar menos informações nos períodos intermediários [...]" (PRONUNCIAMENTO TÉCNICO CPC 21).

Outra possível limitação da pesquisa poderia se achar na questão de que o modelo original de mensuração do conservadorismo condicional utiliza dados das demonstrações contábeis anuais. Por isso, algumas informa- 
ções associadas à política contábil de conservadorismo (registro e evidenciação de eventos ou operações associadas a algumas contas patrimoniais e de resultados) das empresas podem ser omitidas nas demonstrações intermediárias se consideradas materiais, apenas, para a divulgação anual. Como resultado, os lucros contábeis trimestrais podem não estar refletindo, adequadamente, o grau de conservadorismo das empresas, bem como não estar refletindo, oportunamente, os retornos econômicos de períodos intermediários. Entretanto, Givoly et al. (2007) consideram que o uso de dados agregados de um longo período de tempo pode afetar, indevidamente, a mensuração do conservadorismo condicional no modelo de Basu. A sua utilização para estimar a oportunidade assimétrica de reconhecimento de ganhos e perdas no lucro contábil reduz o poder dos testes na presença de conservadorismo em função do efeito Agregação.

Conforme asseveram Givoly et al. (2007), a maneira como o modelo de Basu calcula o conservadorismo condicional não leva em consideração os eventos econômicos individuais e suas consequências, tampouco seus efeitos sobre o resultado contábil. Ao revés disso, observam-se resultados contábeis agregados para o período e o impacto econômico acumulado de eventos do período. Estimar a relação lucro-retorno desses dados agregados pode não gerar o valor esperado para $\beta_{1}$, mesmo que o comportamento subjacente do lucro contábil seja consistente com o conservadorismo. Quanto mais eventos são agregados, maior é o efeito agregação e sua intensidade é em função da duração do período analisado. Desse modo, esse fenômeno é mais susceptível de ser pronunciado em dados anuais do que em dados trimestrais.

\section{RESULTADOS}

Pretendeu-se verificar o sinal e a significância estatísticas de $\beta_{0^{\prime}} \beta_{1}$ e $\alpha_{1}$. As Tabelas $1 \mathrm{e}$ 2 evidenciam os resultados da estatística descritiva para as variáveis Lucro por Ação (LPA) e Retorno Econômico $(R)$.

Tabela 1 Resumo da Estatística Descritiva da Variável Lucro por Ação (LPA) trimestral

\begin{tabular}{l|l}
\hline \multicolumn{2}{c}{ LPA } \\
\hline Média & $-0,09755$ \\
\hline Erro padrão & 0,039398 \\
\hline Mediana & 0,023659 \\
\hline Desvio-padrão & 1,671523 \\
\hline Variância da amostra & 2,793989 \\
\hline Curtose & 663,8484 \\
\hline Assimetria & $-22,7194$ \\
\hline Intervalo & 57,99553 \\
\hline Mínimo & $-54,7143$ \\
\hline Máximo & 3,281252 \\
\hline Soma & $-175,59$ \\
\hline Contagem & 1800 \\
\hline
\end{tabular}

Tabela 2 - Resumo da Estatística

Descritiva da Variável Retorno por Ação (R) trimestral

\begin{tabular}{l|l}
\hline \multicolumn{2}{l}{$R$} \\
\hline Média & 0,075478 \\
\hline Erro padrão & 0,00778 \\
\hline Mediana & 0,040276 \\
\hline Desvio-padrão & 0,330088 \\
\hline Variância da amostra & 0,108958 \\
\hline Curtose & 151,1124 \\
\hline Assimetria & 7,542592 \\
\hline Intervalo & 8,309144 \\
\hline Mínimo & $-0,7475$ \\
\hline Máximo & 7,561644 \\
\hline Soma & 135,8607 \\
\hline Contagem & 1800 \\
\hline
\end{tabular}

Ao todo, foram tabuladas 1.800 observações (100 empresas vezes 18 trimestres) para as duas variáveis. $\mathrm{O}$ maior resultado por ação encontrado foi de $\mathrm{R} \$ 3,28$ e o menor $\mathrm{R} \$-54,71$ indicando uma grande amplitude entre esses 
pontos. O resultado médio por ação foi negativo em $\mathrm{R} \$$-0,097. Em relação ao retorno, o valor médio identificado foi 0,075 . Para a amostra, o maior retorno foi 7,56 e o menor foi $-0,75$. Os dados apontam uma grande amplitude nos valores máximos e mínimos, tanto para LPA quanto para R. Além disso, os coeficientes de variação são 17,13 e 4,37, respectivamente. Esses números podem ser considerados altos, indicando uma forte dispersão entre os dados observados.

As Tabelas 3 e 4 mostram os resultados dos modelos. Para fins de comparação, optou-se por estimar os coeficientes com e sem a variável dummy de trimestre (DT). Com esse procedimento, a intenção foi identificar o efeito da inclusão, no comportamento dos coeficientes, da DT.

Tabela 3 Resultado do modelo de dados em Painel para as empresas não financeiras listadas na Bovespa nos trimestres compreendidos no período de 2005 a 2009, (com nível de significância de $5 \%$.) - Sem DT

\begin{tabular}{|c|c|c|c|c|c|c|}
\hline Variáveis & Coef. & Valor & $\begin{array}{c}\text { Desvio-padrão } \\
\text { Robusto }\end{array}$ & $\mathbf{Z}$ & P-value & \multirow{4}{*}{$\begin{array}{c}\mathrm{R}^{2} \\
\text { ajustado= } \\
0.0020\end{array}$} \\
\hline$D R$ & $\alpha_{1}$ & 0,114234 & 0,0740955 & 1.54 & 0.123 & \\
\hline$R$ & $\beta_{0}$ & 0,139308 & 0,1657602 & 0.84 & 0.401 & \\
\hline$R D R$ & $\beta_{1}$ & $-0,14792$ & 0,284094 & -0.52 & 0.603 & \\
\hline
\end{tabular}

Tabela 4 - Resultado do modelo de dados em Painel para as empresas não financeiras listadas na Bovespa nos trimestres compreendidos no período de 2005 a 2009 (com nível de significância de 5\%). - Com DT

\begin{tabular}{l|c|r|r|r|r|r|}
\hline \multicolumn{1}{c|}{ Variáveis } & Coef. & \multicolumn{1}{c|}{ Valor } & $\begin{array}{c}\text { Desvio-padrão } \\
\text { Robusto }\end{array}$ & Z & P-value \\
\hline$D R$ & $\alpha_{1}$ & 0,097194 & 0,0784598 & 1.24 & 0.215 \\
\hline$R$ & $\beta_{0}$ & 0,137996 & 0,1655526 & 0.83 & 0.405 & $\begin{array}{c}\mathrm{R}^{2} \\
\text { ajustado= } \\
0.0064\end{array}$ \\
\hline$R D R$ & $\beta_{1}$ & $-0,56735$ & 0,5626415 & -1.01 & 0.313 & 0.187 \\
\hline$D T R D R$ & $B 2$ & $-0,12848$ & 0,0974259 & -1.32 & 0.498 \\
\hline
\end{tabular}

Os dados da Tabela 3 apontam que, em base trimestral, não foi encontrada significância estatística para nenhuma variável de interesse $\left(\alpha_{1}, \beta_{0} \mathrm{e} \beta_{1}\right)$ quando não se considera o efeito da Lei n. ${ }^{\circ} 11.638$. Para a amostra em estudo, os resultados indicam que o lucro contábil em trimestres não captura o conservadorismo quando se utiliza o retorno por ação como proxy de boas e más notícias, sugerindo que não existe conservadorismo no lucro das empresas brasileiras que compuseram o estu- do. Esses resultados, em certa medida, estão em consonância com estudos anteriores relacionados à identificação de conservadorismo e à qualidade do lucro divulgado no Brasil (COELHO, CIA e LIMA, 2008; SANTOS e COSTA, 2008; MENDONÇA, 2008; COSTA, 2008; ANTUNES, 2007).

Em relação ao modelo de Basu (1997), ajustado para capturar o feito da Lei n. ${ }^{\circ} 11.638$ (Tabela 4), observe-se que o valor encontrado para o coeficiente $\beta_{1}$ é negativo $(-0,56735)$ e 
estatisticamente não significante, contrário ao que se espera na hipótese de conservadorismo. Nesta mesma direção, o coeficiente $\alpha_{1}$ é positivo e não significativo, contrário ao que se esperava. Dessa maneira, os lucros não incorporam as más notícias mais rapidamente do que as boas notícias. O coeficiente da variável DT $\left(\beta_{3}\right)$, que representa a diferença no grau de conservadorismo antes e depois do dispositivo legal que estabelece o marco regulatório em direção à convergência às normas internacionais, é positivo, mas sem significância estatística. Esse resultado confirma a hipótese $\mathrm{H}_{2}$ de que o grau de conservadorismo não se alterou depois da vigência da Lei 11.638/07.

Outra observação que importa salientar é o valor encontrado para o $\mathrm{R}^{2}$ ajustado. Em ambos os casos (com e sem DT) seu valor é extremamente pequeno, denotando o baixo poder de explicação do modelo para dados trimestrais. Os resultados encontrados estão bem aquém daqueles documentados pela literatura internacional.
Todos os resultados encontrados devem ser avaliados com ressalva, pois utilizam dados de demonstrações contábeis parciais e essas podem, de fato, não incorporar vários ajustes contábeis determinantes do grau de conservadorismo por, circunstancialmente, serem considerados imateriais dentro de períodos trimestrais. Por exemplo, é comum as empresas deixarem para evidenciar algumas provisões apenas nas demonstrações contábeis anuais. Por outro lado, os dados trimestrais servem para controlar o efeito agregação, oferecendo uma medida mais consistente do conservadorismo condicional (GIVOLY et al., 2007), se ele existir.

Para avaliar se os resultados da análise empírica do conservadorismo com dados trimestrais divergem, significativamente, daqueles encontrados a partir de dados anuais, considerando as mesmas empresas da amostra original e uma série histórica mais ampla (1998 a 2007), estimaram-se os coeficientes em base anual. A Tabela abaixo evidencia esses resultados.

Tabela 5 Resultado do modelo de dados em Painel para as empresas não financeiras listadas na Bovespa no período de 1998 a 2007, para um nível de significância de 5\% e demonstrações contábeis anuais

\begin{tabular}{|c|c|c|c|c|c|c|}
\hline Variáveis & Coef. & Valor & $\begin{array}{c}\text { Desvio-padrão } \\
\text { Robusto }\end{array}$ & $\mathbf{Z}$ & P-value & \multirow{4}{*}{$\begin{array}{c}\mathrm{R}^{2} \\
\text { ajustado= } \\
0.0924\end{array}$} \\
\hline$D R$ & $\alpha_{1}$ & $-0,01099$ & 0,1206951 & -0.09 & 0.927 & \\
\hline$R$ & $\beta_{0}$ & 0,202445 & 0,0759656 & 2.66 & 0.008 & \\
\hline$R D R$ & $\beta_{1}$ & $-0,08258$ & 0,3560778 & -0.23 & 0.817 & \\
\hline
\end{tabular}

De acordo com Basu (1997), o coeficiente $\beta_{0}$ apreende o reconhecimento tanto positivo quanto negativo do retorno econômico pelo lucro contábil e evidência o quão a informação contábil é oportuna no reconhecimento do retorno econômico. Por seu turno, o coeficientes $\beta_{1}$ e $\alpha_{1}$ refletem o conservadorismo condicional mediante o reconhecimento assimétrico do retorno econômico pelo lucro contábil. Na hipótese de conservadorismo do lucro (reconhecimento mais oportuno das perdas econômicas), espera-se que o coeficiente $\beta_{1}$ seja positivo, maior e estatisticamente mais significativo que o coeficiente $\beta_{0}$.

Os resultados da Tabela 5 revelam que apenas o coeficiente $\beta_{0}$ é significativo, sendo seu sinal positivo, sugerindo que, para a amostra analisada, as más notícias são divulgadas pela contabilidade oportunamente. Os resultados de $\beta_{1}$ e $\alpha_{1}$ indicam que, apesar 
do sinal negativo (mas sem significância estatística) de $\alpha$, não existe reconhecimento assimétrico de perdas em relação aos ganhos econômicos não realizados. Isso sugere a não existência de conservadorismo condicional. Além disso, observe-se que houve mudança no valor do $R^{2}$ ajustado. Esses achados estão em concordância com os resultados documentados na literatura nacional e internacional que indicam, em geral, que, em países com tradição common law, o lucro contábil é, significativamente, mais oportuno e conservador em comparação com aqueles de tradição civil law.

\section{CONSIDERAÇÕES FINAIS}

A presente pesquisa teve como objetivo precípuo avaliar se, após a vigência da Lei n. ${ }^{\circ}$ 11.638/07, que estabelece o marco regulatório de convergência do padrão contábil nacional para as IFRS, o nível de conservadorismo condicional das empresas brasileiras com ações negociadas na BMF \& BOVESPA modificou.

Os resultados encontrados sugerem que, para as demonstrações contábeis trimestrais, não é possível inferir se as novas normas tiveram algum efeito no grau de reconhecimento assimétrico de perdas econômicas ainda não realizadas em relação aos ganhos, tampouco se, na condição pesquisada, o lucro contábil reflete de forma oportuna o resultado econômico. Tais resultados indicam a rejeição da hipótese testada neste trabalho $\left(\mathrm{H}_{1}\right)$. Desse modo, aceitou-se a hipótese $\mathrm{H}_{2}$ que indica não haver efeito da Lei n. ${ }^{\circ} 11.638$ no conservadorismo condicional das empresas pesquisadas.

A pesquisa apontou, também, que, quando se consideram dados anuais, os resultados convergem para aqueles documentados pela literatura empírica nacional e internacional, porém, o sinal de $\alpha_{1}$ se altera, mas mantém a insignificância estatística. Esse fato sugere que demonstrações contábeis parciais refletem de forma diferente a oportunidade assimétrica de reconhecimento de ganhos e perdas no lucro contábil divulgado no Brasil. Nesse sentido, considerando as consequências do efeito agregação, os resultados aventam que dados anuais talvez não sejam tão tempestivos e confiáveis quanto se gostaria. Em síntese, nesta pesquisa, os dados trimestrais são mais consistentes com a hipótese $\mathrm{H}_{2}$.

Finalmente, conforme já apontado por pesquisas anteriores, a qualidade da informação contábil, que tem no conservadorismo um de seus indicadores mais significativos, decorre do ambiente institucional, dos incentivos que os gestores recebem para a divulgação de relatórios contábeis e do papel que a contabilidade desempenha na resolução de litígios e monitoramento de contratos. Assim, importa observar que, em função do período de tempo abrangido, os resultados apresentados são preliminares e estão limitados pelo modelo de análise de dados adotado, que restringe a realização de inferências e a verificação mais precisa do efeito da mudança do padrão contábil brasileiro no nível de conservadorismo, não levando em consideração outros importantes aspectos relacionados ao processo de adoção das normas internacionais de contabilidade.

\section{Referências}

ANTUNES, Gustavo Amorim. Impacto da adesão aos níveis de governança da BOVESPA na qualidade da informação contábil: uma investigação acerca da oportunidade, relevância e do conservadorismo contábil utilizando dados em painel. Dissertação de Mestrado. FUCAPE, Vitória, 2007.
BALL, R.; SHIVAKUMAR, L. Earnings quality in UK private firms: comparative loss recognition timeliness. Journal of Accounting and Economics, v.39, i.1, p. 83-128, 2005. . The role of accruals in asymmetrically timely 
gain and loss recognition. Journal of Accounting Research, v.44, i.2, p. 207-242, 2006.

Earnings quality in UK private firms: comparative loss recognition timeliness. Journal of Accounting and Economics, v.39, i.1, p.83-128, 2005.

; ROBIN, A.; WU, J. Incentives versus standards: properties of accounting income in four East Asian countries. Journal of Accounting and Economics, v.36, i.1-3, p.235- 270, 2003.

; ASHOK, Robin; GIL, Sadka. Is accounting conservatism due to debt or share markets? A test of "contracting" versus "value relevance" theories of accounting. Working paper, University of Chicago and Rochester Institute of Technology, 2005.

; KOTHARI, S; ASHOK, Robin, A. The effect of international institutional factors on properties of accounting earnings. Journal of Accounting and Economics, v.29, i.1, p.1-51. 2000.

BARTH, M., LANDSMAN, W.; LANG, M. International accounting standards and accounting quality. Working

Paper, Stanford University and University of North Carolina at Chapel Hill, 2006.

BASU, S. The conservatism principle and the asymmetric timeliness of earnings. Journal of Accounting and Economics, v. 24, i.1, p. 3-37, 1997.

BEAVER, W., LAMBERT, R., MORSE, D. The information content of security prices. Journal of Accounting \& Economics, v.2, p.3-28. 1980.

BELKAOUI, A. R. Accounting theory. 5 ed . Cengage Learning EMEA, 2004.

BRASIL. Lei $\mathrm{n}^{\circ} 11.638$, de 28 de dezembro de 2007. Altera e revoga dispositivos da Lei $\mathrm{n}^{\circ} 6.404$, de 15 de dezembro de 1976, e da Lei $n^{\circ} 6.385$, de 7 de dezembro de 1976, e estende às sociedades de grande porte disposições relativas à elaboração e divulgação de demonstrações financeiras. Diário Oficial [da República Federativa do Brasil], Brasília, DF, v. 134, n. 249-A, 28 dez. 2007. Seção 1- Edição Extra.

. Medida Provisória $n^{\circ} 449$, de 3 de dezembro de 2008. Altera a legislação tributária federal relativa ao parcelamento ordinário de débitos tributários, concede remissão nos casos em que especifica, institui regime tributário de transição, e dá outras providências.

Disponível em:<http://www.planalto.gov.br $>$. Acesso em: 02 mar. 2010.

BUSHMAN, R.; PIOTROSKI, J. Financial reporting incentives for conservative accounting: the influence of legal and political institutions. Journal of Accounting and Economics, 2005.

COELHO, A. C.; CIA, J. N. S.; LIMA, I. S.

Conservadorismo condicional na divulgação de lucros: Diferenças entre companhias abertas brasileiras emissoras e não emissoras de ADR'S e entre sistemas contábeis. In: Congresso USP de Controladoria e Contabilidade 2008. Anais..., São Paulo, 2008.

COMISSÃO DE VALORES MOBILIÁRIOS.

Instrução CVM 539, de 14 de março de 2008. Aprova o Pronunciamento Conceitual Básico do CPC que dispõe sobre a Estrutura Conceitual para a Elaboração e Apresentação das Demonstrações Contábeis. Disponível em: < http://www.cvm.gov.br/>. Acesso em: 2 abr. 2010.

\section{COMITÊ DE PRONUNCIAMENTOS CONTÁBEIS.}

Pronunciamento Técnico CPC 21 Demonstração

Intermediária. Disponível em: <http://www.

normaslegais.com. br/legislacao/CPC_21

TermoAprovacao. pdf.> Acesso em: 02 abr. 2010. CONSELHO FEDERAL DE CONTABILIDADE RESOLUÇÃO CFC No 1.055/05, de 7 de outubro de 2005. Cria o Comitê de Pronunciamentos Contábeis - (CPC), e dá outras providências. Disponível em: <http://www. cpc.org.br/pdf/RES_1055.pdf $>$. Acesso em: 18 mai. 2010. CONSELHO FEDERAL DE CONTABILIDADE. RESOLUÇÃO CFC No. 1.121/08, de 28 de março de 2008. Aprova a NBC T 1 - Estrutura Conceitual para a Elaboração e Apresentação das Demonstrações Contábeis. Disponível em: <http://www.cpc.org.br/pdf/ RES_1055.pdf $>$. Acesso em: 18 mai. 2010.

COSTA, A. C. O. Conservadorismo e os países da América do Sul: um estudo da aplicação do conservadorismo em cinco países da América do Sul. Dissertação de Mestrado, FUCAPE. Vitória, 2004.

. O impacto da regulação diferenciada sobre o conservadorismo nas empresas brasileiras: período 1996 2006. Dissertação de Mestrado, FUCAPE. Vitória, 2008 FINANCIAL ACCOUNTING STANDARDS BOARD.

Statement of Financial Accounting Concepts $n .^{\circ} 2$ Qualitative Characteristics of Accounting Information, 1980. Disponível em: <http://www.fasb.org/st/\#fas25>. Acesso em: 05 abr. 2010.

FRANCIS, J.R.; et al. The market pricing of accruals quality. Journal of Accounting and Economics, v.39, i.2, p. 295-327, 2005.

GIVOLY, D.; HAYN, C.. The changing time-series properties of earnings, cash flows and accruals: Has financial reporting become more conservative? Journal of Accounting and Economics, v.29, i.3, p. 287-320, 2000. ; NATARAJAN, A.. Measuring Reporting Conservatism. The Accounting Review, v. 82, i.1, p.65106, 2007.

GONZAGA, R. P. A relação entre conservadorismo contábil e os conflitos entre acionistas sobre politicas de dividendos e o custo da divida: um estudo empírico nas companhias abertas listada na Bovespa. Dissertação de Mestrado, FUCAPE. Vitória, 2008.

; COSTA, F. M. A Relação entre Conservadorismo Contábil e os Conflitos entre Acionistas Majoritários e Minoritários sobre as Políticas de Dividendos nas Empresas Brasileiras Listadas na Bovespa. Revista Contabilidade \& Financas, v. 50, p. 95-109, 2009.

GOTTI, Giorgio. Conditional conservatism in accounting: new measures and test of determinants of the asymmetric timeliness in the recognition of good and bad news in reported earnings. Dissertation Presented for the Doctor of Philosophy Degree The University of Tennessee, Knoxville, May 2007.

HELLMAN, Niclas. Accounting conservatism under IFRS. Accounting in Europe, v.5, n.2, p.71-100, 2008. HENDRIKSEN, Eldon S.; BREDA, Michael F. Van. Accounting theory. 5 ed. Chicago: Irwin, 1991. KAIZER, C. V. C. O impacto da regulamentação contábil sobre o conservadorismo nas empresas do setor elétrico do Brasil. Dissertação de Mestrado, FUCAPE. Vitória, 2007. 
KAM, Vernon. Accounting theory. 2 ed. New York: John Wiley \& Sons, 1990.

LA PORTA, R.; LOPEZ-DE-SILANES, F.; SHLEIFER, A.; VISHNY, R. Law and finance. Journal of Political Economy, v.106, i.6, p. 1113-55, 1998.

MENDONÇA, Mark M. O impacto da lei sarbanesoxley (sox) no conservadorismo contábil das empresas brasileiras que emitiram ADR antes de 2002. Dissertação de Mestrado, FUCAPE. Vitória, 2008.

. O impacto da lei sarbanes-oxley (sox) no conservadorismo contábil das empresas brasileiras que emitiram ADR antes de 2002. Dissertação de Mestrado, FUCAPE. Vitória, 2008.

SANTOS, L. S. R.; COSTA, F. M. Conservadorismo contábil e timeliness: evidências empíricas nas demonstrações contábeis de empresas brasileiras com ADRs negociados na Bolsa de Nova Iorque. Revista Contabilidade \& Finanças, v. 19, p. 27-36, 2008.

SANTOS, S. R. Conservadorismo contábil e timeliness: evidências empíricas nos demonstrativos contábeis em us gaap e br gaap das empresas brasileiras com ADRS negociadas na bolsa de nova iorque. Dissertação de Mestrado, FUCAPE. Vitória, 2006.

SODERSTROM, N.; SUN,K. IFRS adoption and accounting quality: a review. European Accounting Review, v.16, i.4, p. 675-702, 2007.

WATTS, R. L. Conservatism in accounting - part I: explanations and implications. Simon School of Business Working Paper No. FR 03-16, 2003 .Available at SSRN: http://ssrn.com/abstract $=414522$ or doi: $10.2139 /$ ssrn.414522.

. Conservatism in accounting - part II: evidence and research opportunities. Simon Business School Working Paper No. FR 03-25, 2003 Available at SSRN: http://ssrn. com/abstract $=438662$ or doi: $10.2139 /$ ssrn. 438662 .

; ZIMMERMAN, J L. Positive accounting theory. Prentice Hall, Englewood Cliffs, NJ, 1986.

YINPING, J. Essays on accounting conservatism. Thesis, The Hong Kong University. The School of Accounting and Finance, January 2004. 